\title{
Soft tissue perineurioma involving the kidney: a report of two cases with an emphasis on differential diagnosis
}

\author{
Tian-shi Ma', Ling Zhou ${ }^{2}$, Quan Zhou ${ }^{3}$, Xiang-lei He ${ }^{1}$ and Ming Zhao ${ }^{1,4^{*}}$
}

\begin{abstract}
Background: Soft tissue perineurioma of the kidney is rare, with only a few reported cases. We report two additional cases with histologic, immunohistochemical and genetic analyses.

Case presentation: Both tumors were from adults ( 1 female aged 49 years and 1 male aged 42 years) and grossly had maximum diameters of 6.5 and $10 \mathrm{~cm}$, respectively. The tumors were overall well circumscribed but unencapsulated, with focally entrapped benign native renal tubules in one case; both tumors seemed to arise in the capsular areas. The tumors had histologic and immunohistochemical profiles consistent with soft tissue perineurioma. Fluorescence in situ hybridization analyses demonstrated that the tumors were negative for amplification of MDM2 and rearrangements of ESWR1, FUS, and KMT2A. Targeted next-generation sequencing revealed a low tumor mutation burden and likely pathogenic mutations (CYP2B6 and FLT1 mutations for 1 each). Follow-up data were available for both patients; neither had tumor recurrence or metastasis.
\end{abstract}

Conclusions: In conclusion, renal perineurioma is rare, usually arises in the capsular areas, and is cured by resection. Low-grade dedifferentiated liposarcoma and low-grade fibromyxoid sarcoma as well as other spindle cell lesions should be considered in the differential diagnosis.

Keywords: Soft tissue perineurioma, kidney, molecular genetics, dedifferentiated liposarcoma, low-grade fibromyxoid sarcoma

\section{Background}

Perineurioma is a rare and usually benign peripheral nerve sheath tumor composed entirely of cells resembling normal perineurium that includes soft tissue, intraneural, sclerosing and reticular variants $[1,2]$. Soft tissue perineurioma is morphologically characterized by slender spindle cells with delicate bipolar cytoplasm and wavy or tapering nuclei arranged in predominantly

\footnotetext{
* Correspondence: zhaomingpathol@163.com

'Department of Pathology, Laboratory Medicine Center, Zhejiang Provincial People's Hospital, People's Hospital of Hangzhou Medical College, 310014 Hangzhou, Zhejiang, China

${ }^{4}$ Department of Pathology, Zhejiang Provincial People's Hospital, People's Hospital of Hangzhou Medical College, 158 Shangtang Road, 310014 Hangzhou, Zhejiang, China

Full list of author information is available at the end of the article
}

storiform or whorled growth patterns [2]. In immunohistochemistry (IHC) evaluations, perineurioma consistently expresses epithelial membrane antigen (EMA). Claudin-1 and glucose transporter 1 (GLUT1) are also often positive, and CD34 is expressed in approximately $60 \%$ of cases, while staining for S100 protein, SOX10, and glial fibrillary acidic protein (GFAP) is negative[24]. Genetically, soft tissue perineurioma is characterized by deletions of $22 \mathrm{q} 12$ and mutations in NF2 or deletions of 17q11 (including NF1)[5].

Soft tissue perineurioma mostly affects the superficial soft tissues of the extremities and trunk, with approximately $30 \%$ developing in deep soft tissue and very rarely in visceral locations [2]. Soft tissue perineurioma involving the kidney is exceptional, and to our

\section{$\triangle B M C$}

(c) The Author(s). 2021 Open Access This article is licensed under a Creative Commons Attribution 4.0 International License, which permits use, sharing, adaptation, distribution and reproduction in any medium or format, as long as you give appropriate credit to the original author(s) and the source, provide a link to the Creative Commons licence, and indicate if changes were made. The images or other third party material in this article are included in the article's Creative Commons licence, unless indicated otherwise in a credit line to the material. If material is not included in the article's Creative Commons licence and your intended use is not permitted by statutory regulation or exceeds the permitted use, you will need to obtain permission directly from the copyright holder. To view a copy of this licence, visit http://creativecommons.org/licenses/by/4.0/ The Creative Commons Public Domain Dedication waiver (http://creativecommons.org/publicdomain/zero/1.0/) applies to the data made available in this article, unless otherwise stated in a credit line to the data. 
knowledge, only sporadic cases have been reported in the English literature thus far [6-10]. In this article, we present 2 additional cases of soft tissue perineurioma of the kidney and discuss the differential diagnosis.

\section{Case presentation}

\section{Case 1}

A previously healthy 49-year-old female patient was admitted to the hospital due to incidental discovery of a solid mass in the left kidney by abdominal ultrasound. A computed tomography (CT) scan showed a sharply defined, heterogeneously enhancing mass involving the upper pole of the left kidney measuring $5.7 \mathrm{~cm} \times 4.0 \mathrm{~cm}$ in size (Fig. 1A). With the suspicion of a malignant lesion, the patient underwent laparoscopic left partial nephrectomy (including tumor and the surrounding renal parenchyma). The patient recovered well after the operation and had no evidence of tumor recurrence or metastasis at 66 months of follow-up.

Gross examination of the resection specimen revealed a well-demarcated, round and whitish tumor with solid
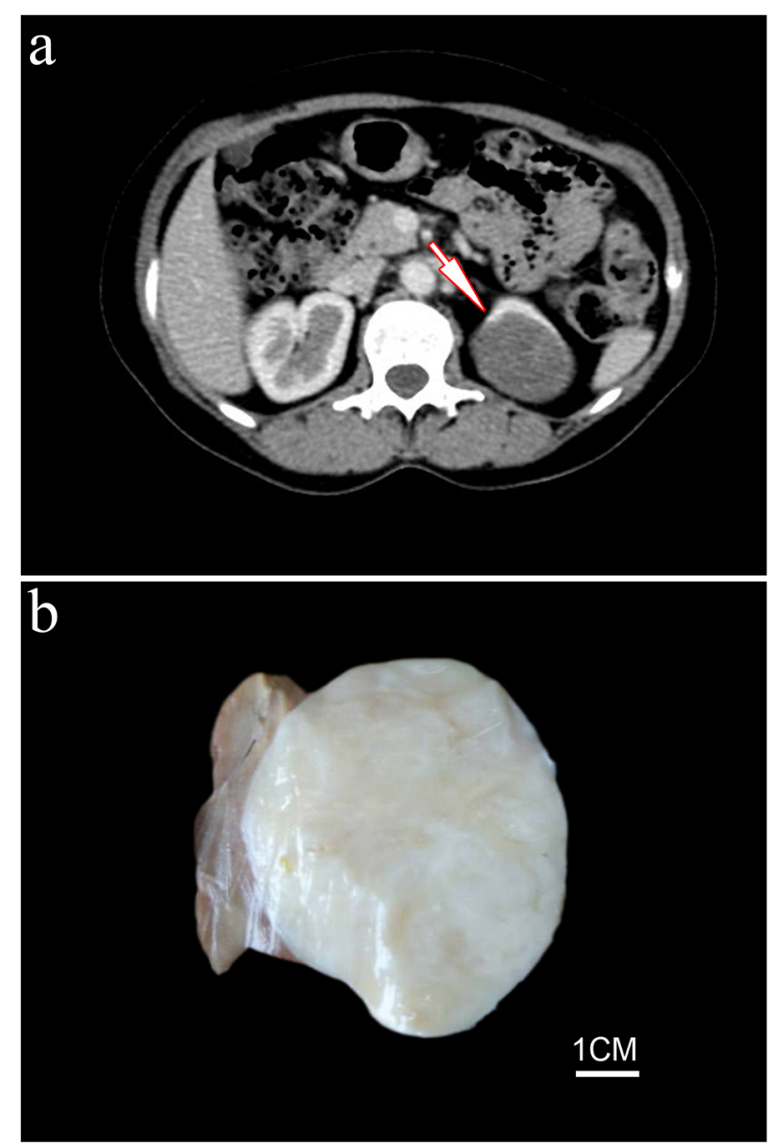

Fig. 1 Case 1. CT scan showed a sharply defined mass involving the upper pole of the left kidney (A, as indicated by arrow). Gross examination revealed a well-demarcated, round and whitish, solid tumor (B) and firm texture $(6.5 \mathrm{~cm} \times 5.0 \mathrm{~cm} \times 4.0 \mathrm{~cm})$ (Fig. 1B). Microscopically, the tumor was well circumscribed overall but unencapsulated, with focally entrapped benign dilated native renal tubules (Fig. 2A).The tumor cells were arranged in concentric whorls, in interwoven fascicles or in a storiform pattern, set in varying amounts of myxoid and collagenous matrix (Fig. 2B, C). The tumor cells were elongated, spindle-shaped cells with minimal, slightly eosinophilic cytoplasm and ovoid to tapering, bland-appearing nuclei (Fig. 2D). No mitosis or tumor necrosis were identified. Vascularities were scarce and stag-horn shaped, and dilated vessels were occasionally seen.

IHC revealed that the tumor cells showed diffuse and faint EMA positivity with a delicate bipolar staining pattern (Fig. 3A), focally positive staining for MUC4 (in less than $10 \%$ tumor cells)(Fig. 3B), claudin-1(in 10\%-15\% tumor cells) (Fig. 3C) and CD34 (in less than $5 \%$ tumor cells with a similar staining pattern with EMA)(Fig. 3D), and negative staining for GLUT1, S100 protein, estrogen receptor, progesterone receptor, DOG1, smooth muscle actin (SMA), HMB45 and STAT6. Fluorescence in situ hybridization (FISH) analyses demonstrated that the tumor cells were negative for amplification of $M D M 2$ (Fig. 3E), and rearrangements of FUS (Fig. 3F), EWSR1, and KMT2A. Genetic testing using targeted nextgeneration sequencing (NGS) for 425 cancer-relevant genes (Gene seqPrime) revealed a low tumor mutation burden (TMB) (1.1 mutations per megabase) and a likely pathogenic mutation of CYP2B6 (NM_000767.5) at chromosome 19:41,515,212 of exon5 c.734T > C(p.I245T, missense variant), which has a variant allele frequency (VAF) of $25.0 \%$ (Fig. 4). No genomic alterations in NF1 or NF2 were present.

\section{Case 2}

A 42-year-old man presented with abdominal discomfort of 1 month. The physical examination revealed a hard mass over his left upper quadrant and knocking tenderness in the left flank area. His medical history was unremarkable, and laboratory findings revealed no abnormalities. An abdominal CT scan indicated a large tumor with a hypodense lesion and a well-defined margin in the left perirenal space. A left partial nephrectomy was performed. The patient recovered well after surgery, and no evidence of local recurrence or distant metastasis was noted on imaging 24 months later.

Grossly, the tumor measured $10 \mathrm{~cm}$ in maximum diameter and was well defined with a clear boundary separating the tumor from the surrounding thin renal tissue. The tumor was white to yellowish in color and soft to firm in consistency (Fig. 5A). Histologically, at lower magnification, the tumor was clearly demarcated from the surrounding renal parenchyma, which seemed 


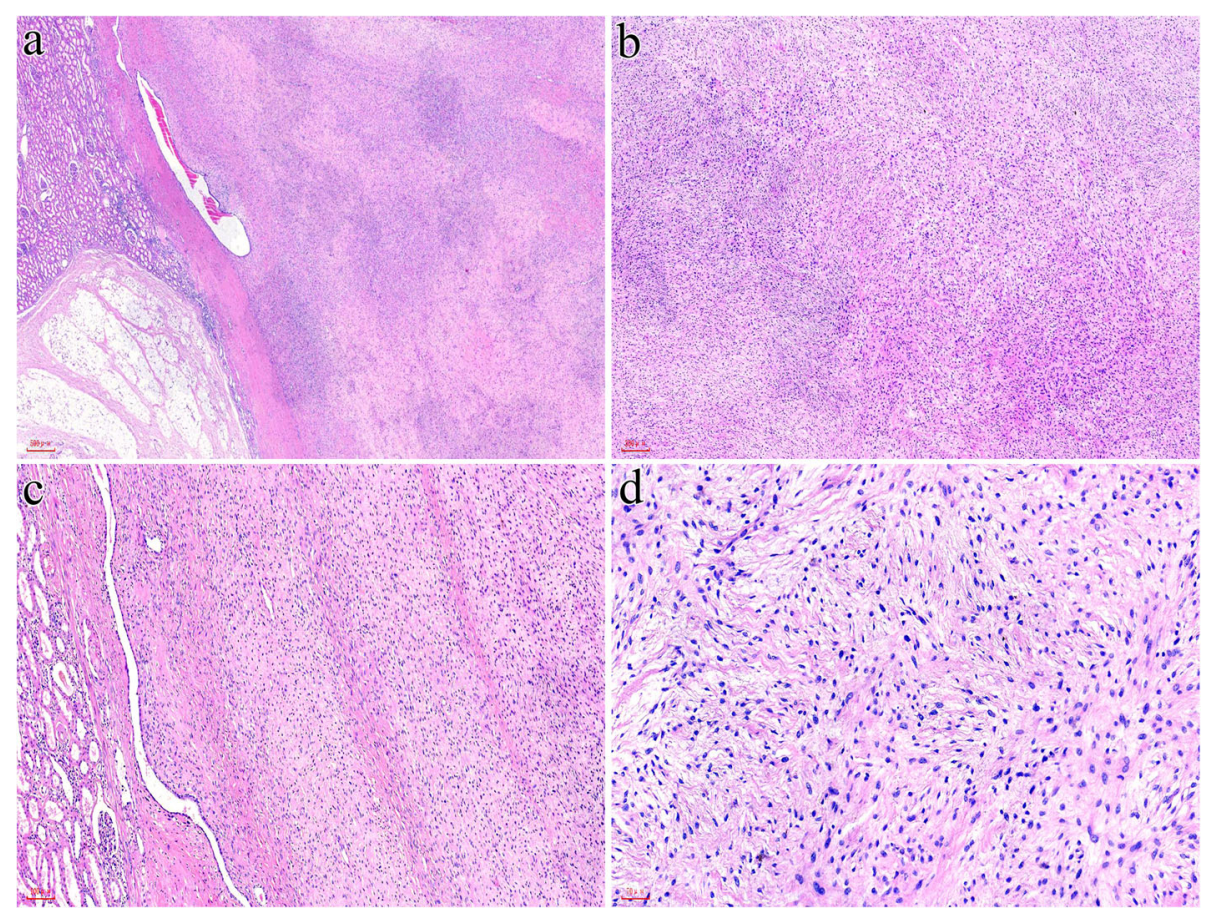

Fig. 2 Microscopically, the tumor was unencapsulated with focally entrapped benign renal tubules (A). The tumor cells were arranged in interwoven fascicles or storiform patterns in a myxoid to collagenous matrix (B, C). The tumor cells were elongated, spindle-shaped cells with ovoid to tapering, bland-appearing nuclei (D)

to originate from the renal capsule (Fig. 5B). In general, the tumor was hypocellular and showed alternating zones of collagenous and mucinous stroma (Fig. 5C). It was composed of spindle cells with tapering nuclei and elongated bipolar cytoplasmic processes arranged in a storiform and whorled architecture surrounding thinwalled small blood vessels (Fig. 5D). No atypia, mitosis or tumor necrosis was noted.

IHC analyses revealed that the tumor cells were positive for EMA (Fig. 6A) and CD34 (Fig. 6B) and negative for claudin-1, GLUT1, S100 protein, MUC4, STAT6, SMA, HMB45 and P16. FISH studies demonstrated that the tumor was negative for amplification of $M D M 2$ and rearrangements of EWSR1 (Fig. 6C), FUS, and KMT2A (Fig. 6D). Genetic testing using targeted NGS for 425 cancer-relevant genes (Gene seqPrime) revealed a low level of TMB ( 0 mutations per megabase) and a likely pathogenic mutation of FLT1 (NM_002019.4) at chromosome 13:28,964,050 with exon 13 c.1852 $A>$ $T(p . T 618 S$, missense variant), which has a VAF of $1.5 \%$ (Fig. 7). No genomic alterations in NF1 or NF2 were present.

\section{Discussion and conclusions}

Soft tissue perineurioma involving the retroperitoneum is rare, and that arising in the kidney is even rarer. In Hornick and Fletcher's [2] report, only 3/81 (3.7\%) of soft tissue perineuriomas originated in the retroperitoneum, and none was specified to affect the kidney.

A MEDLINE search revealed 6 cases (in 4 patients) of renal perineurioma in English-language publications[610](References[7]and[8] reported the same case). At present, we present two additional cases of soft tissue perineurioma involving the kidney, both of which seemed to arise in the capsular areas of the kidney. A summary of the 8 cases of renal perineurioma reported in the literature, including the 2 cases reported in this article, found that these tumors mainly occurred in adults and rarely in children, and all were sporadically without neurofibromatosis type 1 or 2 , and they could be discovered accidentally or presented with symptoms due to local compression and irritation (Table 1). Compared with its superficial counterparts, renal perineurioma has a relatively larger diameter, as evidenced by the findings of a previous study that deep-seated tumors were larger in size than subcutaneous tumors[2]. Soft tissue perineurioma is typically benign and rarely recurs. Case 1 in our study showed entrapment of benign native renal tubules, which suggested locally invasive growth and gave an impression of a low-grade malignant tumor. However, atypical histologic features, including scattered pleomorphic tumor cells and infiltrative margins, usually have no clinical significance in the absence of frankly malignant features[2]. Including our 2 cases, all the 


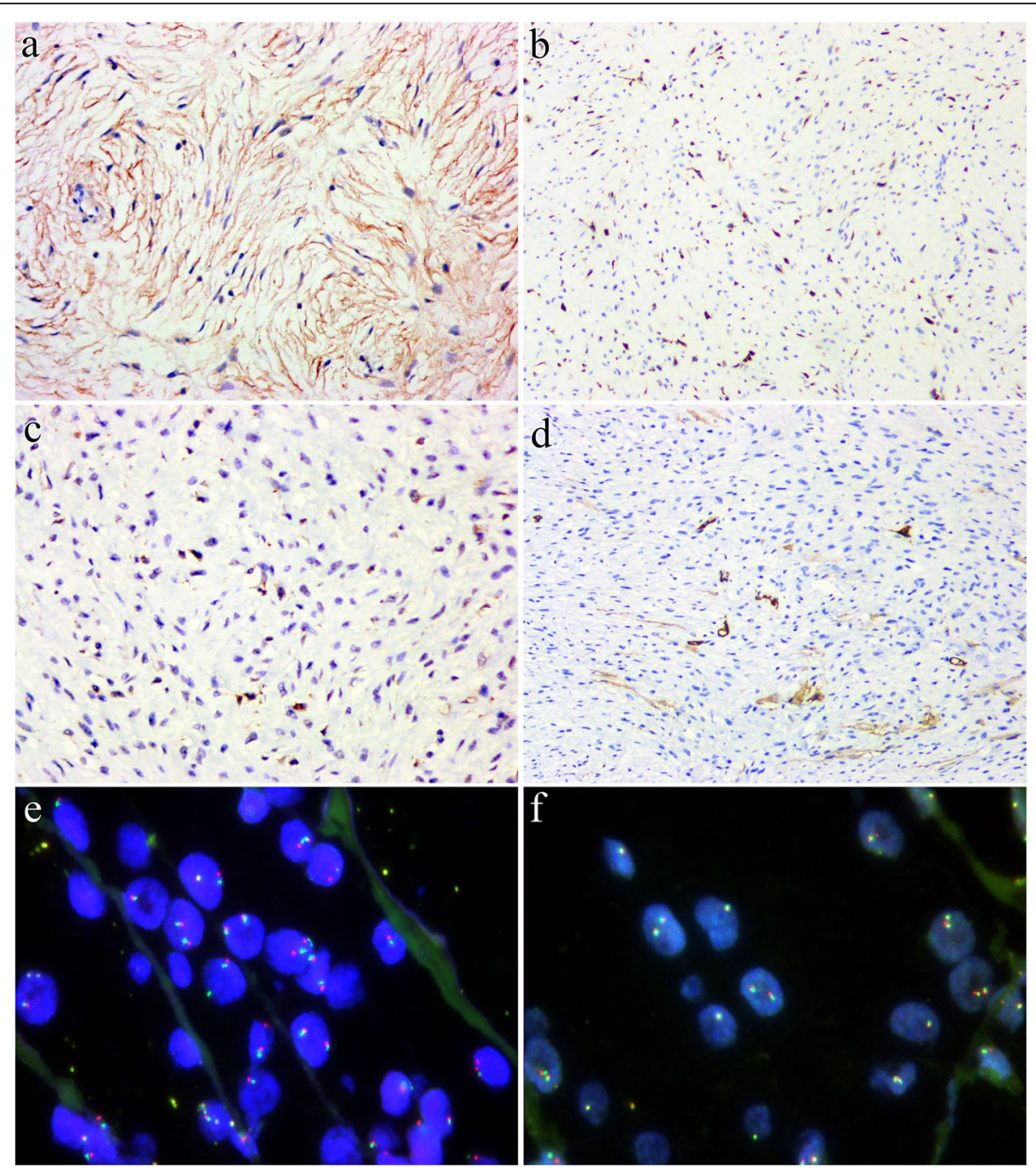

Fig. 3 Immunohistochemically, the tumor cells showed diffuse and faint EMA positivity (A) and focally positive staining for MUC4 (B), claudin-1 $(\mathbf{C})$, and CD34 (D). FISH analysis revealed that the tumor cells were negative for MDM2 amplification (E, red signals: MDM2; green signals: CEP12) and FUS rearrangement (F, red signals: 5' FUS; green signals: 3' FUS)

\section{CYP2B6:NM_000767.5:exon5 c.734T>C(p.I245T)}

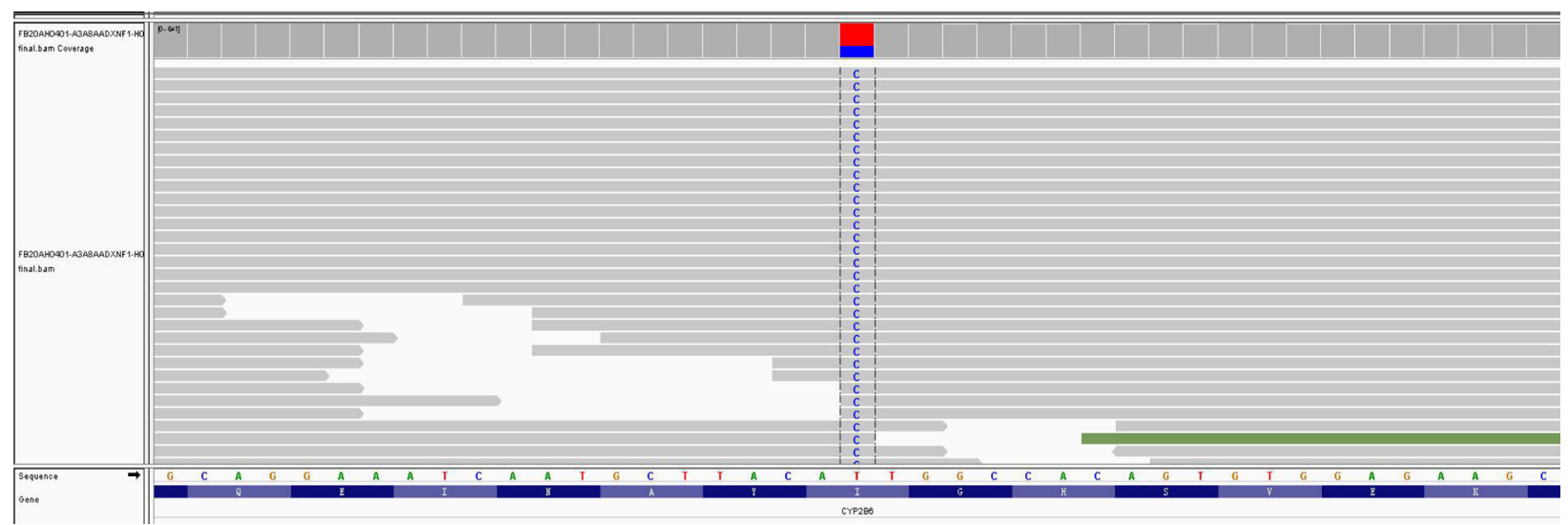

Fig. 4 Integrative Genomics Viewer (IGV) split-screen view of read alignments of the identified mutations of CYP2B6:NM_000767.5:exon5 C.734T > $C(p .1245 T)$ in case 1 

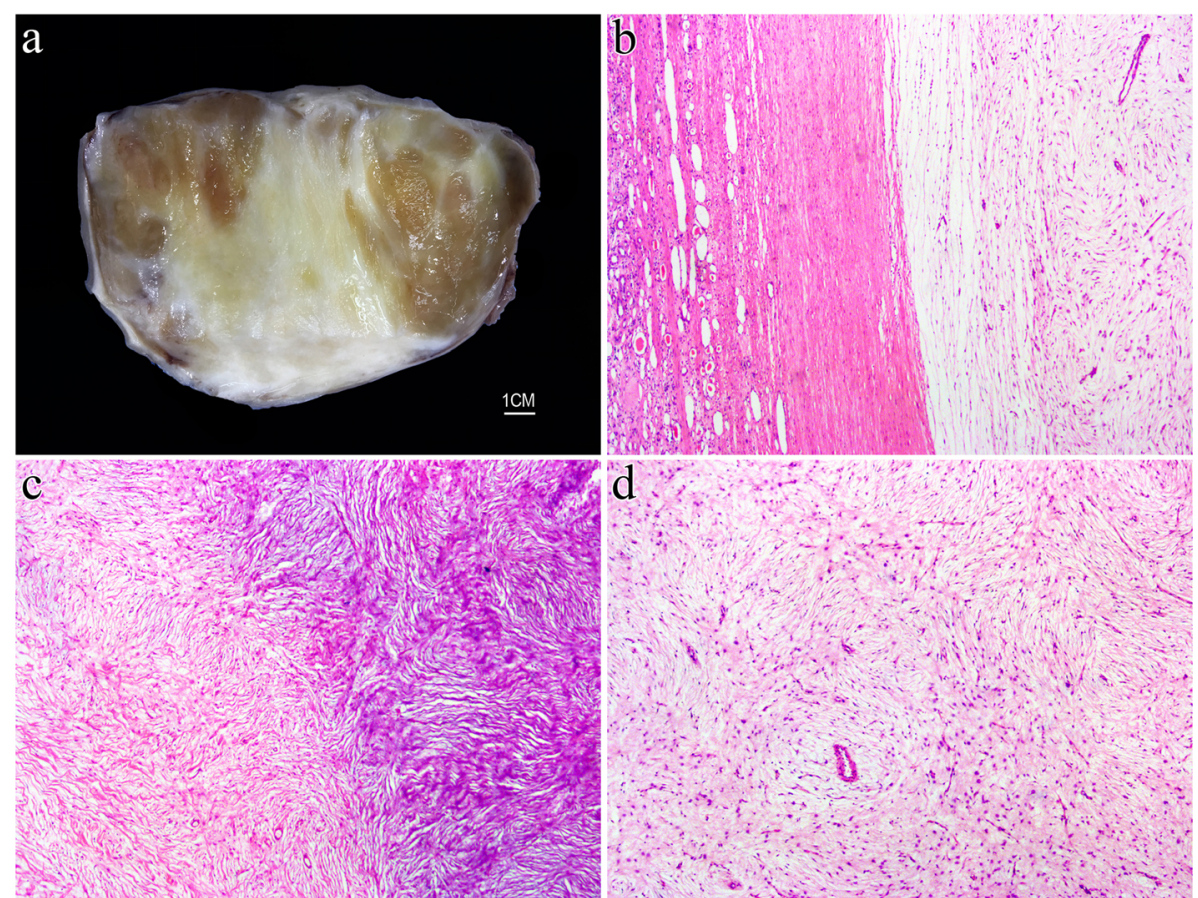

Fig. 5 Case 2. Macroscopic examination showed a well-defined tumor with a clear boundary to the surrounding thin renal tissue that was white to yellowish in color (A). The tumor was clearly demarcated from the surrounding renal parenchyma and seemed to originate from the renal capsule (B). The tumor showed alternating zones of collagenous and mucinous stroma (C) and consisted of spindle cells with elongated bipolar cytoplasmic processes arranged in storiform and whorled patterns (D)

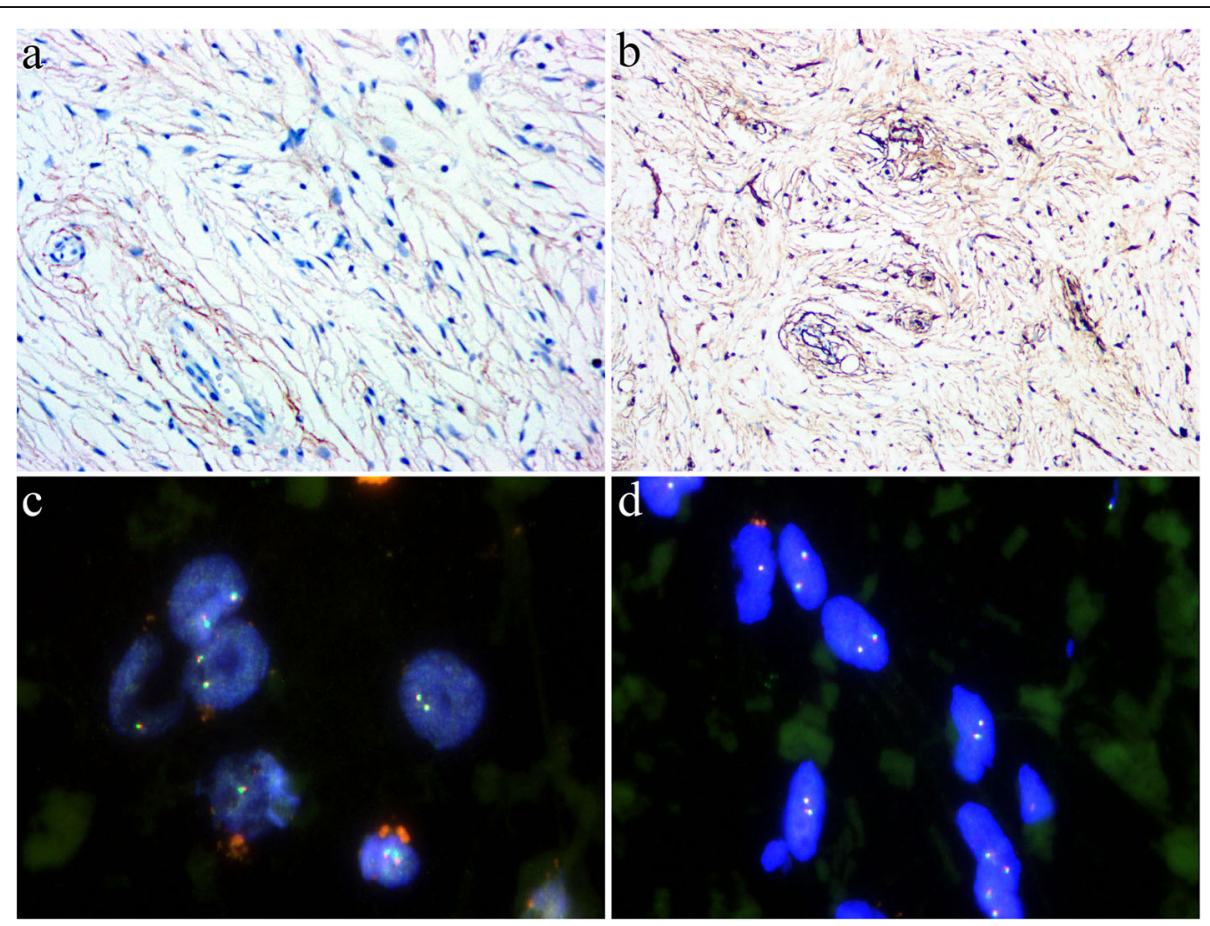

Fig. 6 The tumor cells exhibited diffuse and weak expression of EMA (A) and CD34 (B). In FISH analyses, the tumor cells were negative for rearrangements of EWSR1 (C, red signals: 5' of EWSR1; green signals: 3' of EWSR1) and KMT2A (D, red signals: 5' of KMT2A; green signals: 3' of KMT2A) 


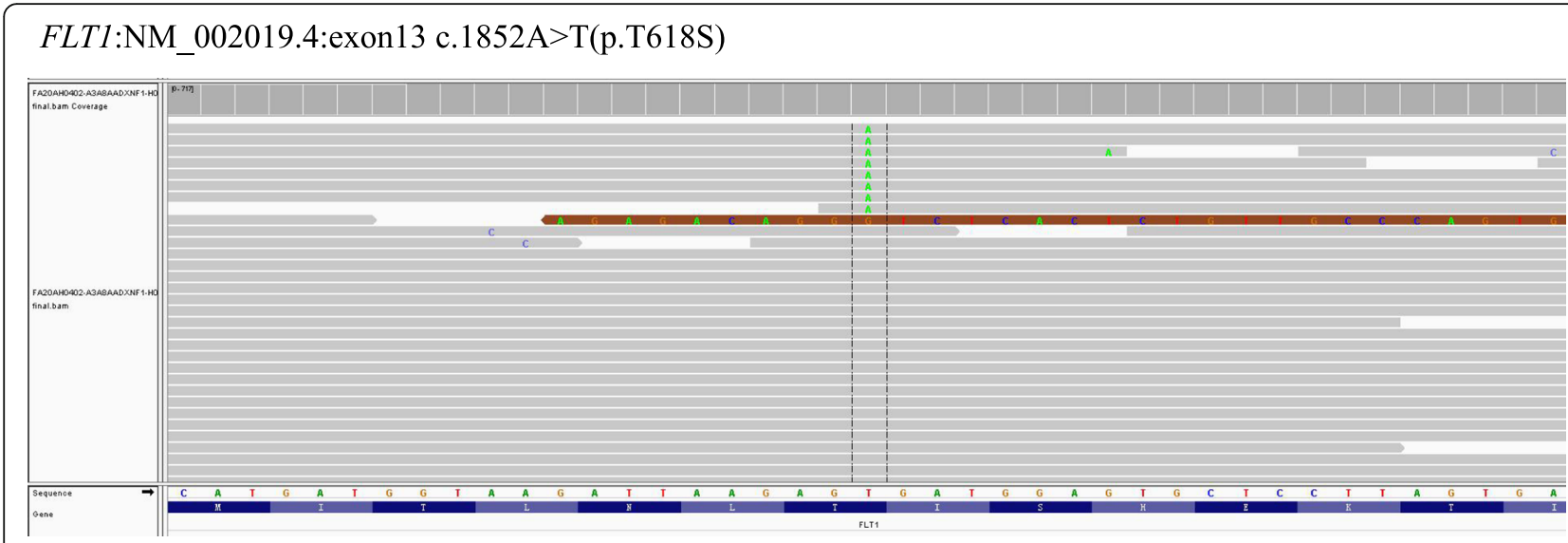

Fig. 7 Integrative Genomics Viewer (IGV) split-screen view of read alignments of the identified mutations of FLT1:NM_002019.4:exon13 C.1852 A > T(p.T618S) in case 2

reported patients with renal perineurioma underwent surgery alone, and none had tumor recurrences during follow-up when available [6-10].

With regard to soft tissue perineurioma of the kidney, the differential diagnoses were broad and principally included neurofibroma, schwannoma, solitary fibrous tumor, and spindle cell predominant angiomyolipoma in the kidney. Familiarity with its unique morphological features, including storiform or whorled arrangements of slender spindle cells with delicate bipolar cytoplasmic processes with wavy or tapering nuclei, supplemented by the frequent immunoexpression of EMA, claudin-1 and GLUT1 as well as absence of expression of S100 protein, SOX10, STAT6, HMB45, and SMA/desmin, can usually distinguish renal perineurioma from the other entities mentioned above.

Clinically, the most important differential diagnosis is from low-grade dedifferentiated liposarcoma (DDLPS) and low-grade fibromyxoid sarcoma (LGFMS), both of which can extend into and become secondarily involved in the kidney as a primary tumor in the retroperitoneal regions. DDLPS by definition is an atypical lipomatous tumor/well-differentiated liposarcoma showing transition to nonlipogenic sarcoma, which in most cases is of high grade and uncommonly exhibits low-grade histologic features [11]. Low-grade DDLPS is characterized by the presence of relatively uniform fibroblastic-like spindle cells with moderate cellularity and mild nuclear atypia, often rearranged in fascicular and infrequently storiform patterns, which may mimic soft tissue perineurioma histologically. In addition, CD34 has also been expressed in a subset of DDLPS [12], and rare soft tissue perineuriomas may show "pseudolipoblastic" morphology [13], further complicating the differential diagnosis. Perhaps the most difficult situation is to distinguish between soft tissue perineurioma of the kidney with DDLPS with a peculiar meningothelial-like whorl growth pattern $[14,15]$, especially on biopsy specimens. This

Table. 1 Summary of the clinicopathologic features of soft tissue perineurioma of the kidney

\begin{tabular}{|c|c|c|c|c|c|}
\hline Study & Case No. & Sex/Age & Clinical manifestations & Lateral/Size & Follow-up(m) \\
\hline Kahn et al. [6] & 1 & Female/66 years & $\begin{array}{l}\text { Incidentally identified during evaluation of } \\
\text { hypertension and proteinuria }\end{array}$ & NA & NA \\
\hline $\begin{array}{l}\text { Val-Bernal et al. [7] a } \\
\text { and García-Valtuille et al. [8] a }\end{array}$ & 2 & Female/7 years & Fever $\left(38.5^{\circ} \mathrm{C}\right)$, nausea and abdominal pain. & Right $/ 3 \mathrm{~cm}$ & NA \\
\hline \multirow[t]{3}{*}{ Huang et al. [9] } & $3^{b}$ & Male/25years & $\begin{array}{l}\text { Progressive left flank distention and dyspepsia } \\
\text { for } 3 \text { months }\end{array}$ & Left/14 cm & NED/24 \\
\hline & $4^{b}$ & & & Left/10 cm & \\
\hline & $5^{\mathrm{b}}$ & & & Right/6 cm & \\
\hline Gan et al. [10] & 6 & Male/40years & $\begin{array}{l}\text { Incidentally discovered in the nonfunctioning } \\
\text { graft by routine imaging surveillance }\end{array}$ & $\begin{array}{l}\text { Right transplanted } \\
\text { kidney/12 cm }\end{array}$ & NA \\
\hline Current case 1 & 7 & Female/49years & Incidentally discovered by abdominal ultrasound & Left/ $6.5 \mathrm{~cm}$ & NED/66 \\
\hline Current case 2 & 8 & Male/42years & Abdominal discomfort of 1 month's duration & Left/12 cm & NED/24 \\
\hline
\end{tabular}

NED: no evidence of disease

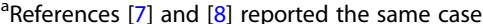

${ }^{\mathrm{b}}$ Cases 3-5 were concurrent in the same patient. 
distinctive variant of DDLPS is usually located in the retroperitoneum and shares many features with soft tissue perineurioma, including low-grade spindle cells with concentric distributions and frequent expression of claudin-1 by IHC [14]. However, DDLPS with meningothelial-like whorls is commonly associated with metaplastic bone formation and exhibits coexpression of P16, CDK4, and MDM2 [14], markers that are usually negative in soft tissue perineurioma. In difficult cases, FISH analysis for detecting 12q1415 (including $M D M 2$ and $C D K 4$ ) amplification, the genetic hallmark of DDLPS, can serve as a robust tool to distinguish DDLPS from soft tissue perineurioma.

Perhaps the closest histologic mimic of soft tissue perineurioma of the kidney is LGFMS, which arises most commonly in deep soft tissue of the extremities and occasionally in the abdominal cavity and retroperitoneum [16]. LGFMS is a low-grade malignant fibroblastic tumor and is related to sclerosing epithelioid fibrosarcoma (SEF) both morphologically and molecularly. LGFMS demonstrates considerable histologic and immunohistochemical overlaps with soft tissue perineurioma, including deceptive bland spindle cells with fascicular or whoring patterns in alternating collagenous and myxoid stroma. By IHC both tumors largely express EMA. In addition, a subset of LGFMS has been reported to have a perineurioma-like morphology that frequently shows strong expression of claudin-1[17]. However, the prominent arcades of small blood vessels typical of LGFMS are usually absent in soft tissue perineurioma. Moreover, giant collagen rosette formation, a distinctive feature in a subset of LGFMS, is very uncommonly seen in soft tissue perineurioma[18]. LGFMS is genetically characterized by $\mathrm{t}(7 ; 16)(\mathrm{q} 33 ; \mathrm{p} 11)$ with resultant FUS-CREB3L2 fusion in approximately $75 \%$ of cases. Rare cases harboring fusion variants of FUS-CREB3L1 and EWSR1CREB3L1 have been described [19]. MUC4, an epithelial glycoprotein, has been found to serve as a highly sensitive and specific marker for LGFMS and is expressed in approximately $99 \%$ of cases with usually diffuse and strong staining [20]. In a study by Doyle et al. [20], MUC4 was found to be negative in all forty cases of soft tissue perineurioma included and was indicated to be helpful for the differentiation between LGFMS and perineurioma. Most recently, Plus et al. [21]found that tumors within the spectrum of LGFMS and SEF but lacking MUC4 expression and FUS/EWSR1-CREB3L fusion harbored a novel YAP1-KMT2A fusion, potentially expanding the genetic spectrums of these related tumors. In case 1 of our report, MUC4 was expressed in less than $10 \%$ tumor cells, raising the suspicion of LGFMS. However, positivity for CD34 by IHC, which is very uncommon in LGFMS, and negativity for rearrangements of FUS and EWSR1 by FISH analyses excluded the possibility of LGFMS. Both our cases were negative for $K M T 2 A$ rearrangements, which can further help with differentiation.

Cytogenetically, soft tissue perineurioma shares similar pathogenic mechanisms with those of other nerve sheath tumors. Deletion of 22q12 and mutations in NF2 are the most frequently reported genetic abnormalities. Deletion of 17q11 (including NF1) is also a recurrent event in a subset of cases [5]. In the present report, we performed targeted NGS for 425 cancer-relevant genes, including $N F 1$ and NF2, in both tumors, which revealed low levels of TMB and likely pathogenic mutations with CYP2B6 and FLT1 mutations for 1 each; however, no genomic alterations in NF1 or NF2 were identified. CYP2B6, located at $19 \mathrm{q} 13.2$, is a polymorphic detoxification gene that plays a vital role in the degradation of genotoxic compounds. Single nucleotide polymorphisms in the $C Y P 2 B 6$ gene locus, which result in reduced enzymatic activity, have been associated with many types of solid tumors, mainly hematological malignancies [22]. FLT1, also known as vascular endothelial growth factor receptor-1 (VEGFR-1), is located at 13q12.3 and encodes a member of the VEGFR family. VEGFR family members are receptor tyrosine kinases and serve as critical mediators of tumor angiogenesis and vessel permeability. VEGFR-1 has been detected in schwannoma, and increased levels of this factor correlate with increased rates of tumor growth [23]. Mutations of CYP2B6 and FLT1 have not been reported in soft tissue perineurioma, and the pathogenic significance of these mutations is largely unknown. It is worth collecting more cases for further in-depth study to determine whether these are novel potential pathogenic mutations in soft tissue perineurioma.

In summary, soft tissue perineurioma rarely arises from the kidney and is usually located in the capsular areas. Although atypical histologic features such as local invasive growth can be seen, the clinical behavior is benign. Lowgrade DDLPS and LGFMS as well as other spindle cell lesions should be considered in the differential diagnosis.

\section{Abbreviations \\ $C T$ : computed tomography; DDLPS: dedifferentiated liposarcoma; EMA: epithelial membrane antigen; FISH: fluorescence in situ hybridization; GFAP: glial fibrillary acidic protein; GLUT1: glucose transporter 1; \\ IHC: immunohistochemistry; LGFMS: low-grade fibromyxoid sarcoma; NGS: next generation sequencing; SEF: sclerosing epithelioid fibrosarcoma; SMA: smooth muscle actin; TMB: tumor mutation burden; VAF: variant allele frequency; VEGFR-1: vascular endothelial growth factor receptor - 1}

\section{Acknowledgements}

The authors thank Shao-yu Chen, PhD from Anbiping Laboratory, Guangzhou, China, for helping with FISH analyses in the two cases.

\section{Authors' contributions}

TM, MZ: conception and design of the work, acquisition, analysis and interpretation of data, drafting the manuscript and revising it critically for important intellectual content and scientific integrity. TM, LZ, QZ, XH, MZ: acquisition, analysis and interpretation of data, reading and revising the 
manuscript critically for important intellectual content and scientific integrity. All authors have read and approved the final manuscript.

\section{Funding}

This study was supported by Zhejiang Provincial Natural Science Foundation (LY21H160052), and Zhejiang Provincial Medicine and Health Research Foundation (2018KY246, 2019KY020)

\section{Availability of data and materials}

Records and data pertaining to both the cases are in the patient's secure medical records in Zhejiang Provincial People's Hospital, People's Hospital of Hangzhou Medical College. All searched data by literature review are included in this paper.

\section{Declarations}

\section{Ethics approval and consent to participate}

Samples were used in accordance with ethical guidelines for the use of retrospective tissue samples provided by the local ethics committee of the Zhejiang Provincial People's Hospital, People's Hospital of Hangzhou Medical College.

\section{Consent for publication}

Written informed consent was obtained from the patient for publication of this case report and any accompanying images. A copy of the consent form is available for review by the Editor of this journal.

\section{Competing interests}

The authors declare that they have no competing interests.

\section{Author details}

'Department of Pathology, Laboratory Medicine Center, Zhejiang Provincial People's Hospital, People's Hospital of Hangzhou Medical College, 310014 Hangzhou, Zhejiang, China. 'Department of Pathology, People's Hospital of Lichuan, 445499 Lichuan, Hubei, China. ${ }^{3}$ Department of Pathology, Jiaxing Second Hospital, 314099 Jiaxing, Zhejiang, China. ${ }^{4}$ Department of Pathology, Zhejiang Provincial People's Hospital, People's Hospital of Hangzhou Medical College, 158 Shangtang Road, 310014 Hangzhou, Zhejiang, China.

Received: 13 May 2021 Accepted: 20 September 2021

Published online: 30 September 2021

\section{References}

1. Hornick JL, Carter JM, Creytens D. Perineurioma. WHO Classification of Tumours Editorial Board. Soft tissue and bone tumours, 5th, ed. Lyon: International Agency for Research on Cancer; 2020, pp. 237-9.

2. Hornick JL, Fletcher CD. Soft tissue perineurioma: clinicopathologic analysis of 81 cases including those with atypical histologic features. Am J Surg Pathol. 2005:29(7):845-58.

3. Folpe AL. Billings SD, McKenney JK. Walsh SV, Nusrat A. Weiss SW. Expression of claudin-1, a recently described tight junction-associated protein, distinguishes soft tissue perineurioma from potential mimics. Am J Surg Pathol. 2002;26(12):1620-6.

4. Agaimy A. Buslei R, Coras R. Rubin BP, Mentzel T. Comparative study of soft tissue perineurioma and meningioma using a five-marker immunohistochemical panel. Histopathology. 2014;65(1):60-70.

5. Carter JM. Wu Y, Blessing MM. Folpe AL, Thorland EC. Spinner RJ, Jentoft ME. Wang C, Baheti S. Niu Z, Mauermann ML. Klein CJ. Recurrent Genomic Alterations in Soft Tissue Perineuriomas. Am J Surg Pathol. 2018;42(12): 1708-14.

6. Kahn DG. Duckett T, Bhuta SM. Perineurioma of the kidney. Report of a case with histologic, immunohistochemical, and ultrastructural studies. Arch Pathol Lab Med. 1993:117(6):654-7.

7. Val-Bernal JF. Hernando M, Garijo MF. Villa P. Renal perineurioma in childhood. Gen Diagn Pathol. 1997;143(1):75-81.

8. García-Valtuille R. Abascal F, Ortuzar Jl. Otero M, Vidal JA. Perineurioma (storiform perineurial fibroma) of the kidney in a child. Eur Radiol. 1998;8(5): 770-1.

9. Huang CY. Tsai JW, Lin VC. Yu TJ. Bilateral renal myxoid perineuriomas. Am J Med Sci. 2012;343(3):265-6.
10. Gan VH. Wan WK, Tan YH. Myxoid perineurioma in a transplanted kidney. Transplant Proc. 2014:46(1):286-9.

11. Henricks WH. Chu YC, Goldblum JR. Weiss SW. Dedifferentiated liposarcoma: a clinicopathological analysis of 155 cases with a proposal for an expanded definition of dedifferentiation. Am J Surg Pathol. 1997;21(3):271 - 81.

12. Hasegawa T. Seki K, Hasegawa F. Matsuno Y, Shimodo T. Hirose T, Sano T. Hirohashi S. Dedifferentiated liposarcoma of retroperitoneum and mesentery: varied growth patterns and histological grades-a clinicopathologic study of 32 cases. Hum Pathol. 2000;31(6):717 - 27.

13. Torres-Mora J. Ud Din N, Ahrens WA. Folpe AL. Pseudolipoblastic perineurioma: an unusual morphological variant of perineurioma that may simulate liposarcoma. Hum Pathol. 2016;57(1):22-7.

14. Thway K. Robertson D, Thway Y. Fisher C. Dedifferentiated liposarcoma with meningothelial-like whorls, metaplastic bone formation, and CDK4, MDM2, and 16 expression: a morphologic and immunohistochemical study. Am J Surg Pathol. 2011;35(3):356 - 63.

15. Fanburg-Smith JC. Miettinen M. Liposarcoma with meningothelial-like whorls: a study of 17 cases of a distinctive histological pattern associated with dedifferentiated liposarcoma. Histopathology. 1998;33(5):414 - 24.

16. Ud Din N. Ahmad Z, Zreik R. Horvai A, Folpe AL. Fritchie K. Abdominopelvic and Retroperitoneal Low-Grade Fibromyxoid Sarcoma: A Clinicopathologic Study of 13 Cases. Am J Clin Pathol. 2018;149(2):128 - 34

17. Thway K. Fisher C, Debiec-Rychter M. Calonje E. Claudin-1 is expressed in perineurioma-like low-grade fibromyxoid sarcoma. Hum Pathol. 2009;40(11): 1586-90.

18. Creytens D. Ferdinande L, Van Dorpe J. A Sclerosing Perineurioma With Collagen Rosette Formation: Benign Mimic of Low-Grade Fibromyxoid Sarcoma. Int J Surg Pathol. 2018;26(2):145-7.

19. Lau PP. Lui PC, Lau GT. Yau DT, Cheung ET. Chan JK. EWSR1-CREB3L1 gene fusion: a novel alternative molecular aberration of low-grade fibromyxoid sarcoma. Am J Surg Pathol. 2013;37(5):734-8.

20. Doyle LA. Möller E, Dal Cin P. Fletcher CD, Mertens F. Hornick JL. MUC4 is a highly sensitive and specific marker for low-grade fibromyxoid sarcoma. Am J Surg Pathol. 2011;35(5):733 - 41.

21. Puls F. Agaimy A, Flucke U. Mentzel T, Sumathi VP. Ploegmakers M, Stoehr R Kindblom LG, Hansson M. Sydow S, Arbajian E. Mertens F. Recurrent Fusions Between YAP1 and KMT2A in Morphologically Distinct Neoplasms Within the Spectrum of Low-grade Fibromyxoid Sarcoma and Sclerosing Epithelioid Fibrosarcoma. Am J Surg Pathol. 2020;44(5):594-606.

22. Daraki A. Kakosaiou K, Zachaki S. Sambani C, Aleporou-Marinou V. Kollia P, Manola KN. Polymorphisms and haplotypes of the CYP2B6 detoxification gene in the predisposition of Acute Myeloid Leukemia (AML) and induction of its cytogenetic abnormalities. Cancer Genet. 2016;209(11):525 - 33.

23. Cayé-Thomasen P. Werther K, Nalla A. Bøg-Hansen TC, Nielsen HJ. Stangerup SE, Thomsen J. VEGF and VEGF receptor-1 concentration in vestibular schwannoma homogenates correlates to tumor growth rate. Otol Neurotol. 2005;26(1):98-101.

\section{Publisher's Note}

Springer Nature remains neutral with regard to jurisdictional claims in published maps and institutional affiliations.

Ready to submit your research? Choose BMC and benefit from:

- fast, convenient online submission

- thorough peer review by experienced researchers in your field

- rapid publication on acceptance

- support for research data, including large and complex data types

- gold Open Access which fosters wider collaboration and increased citations

- maximum visibility for your research: over $100 \mathrm{M}$ website views per year

At BMC, research is always in progress.

Learn more biomedcentral.com/submissions 